TAPROBANICA, ISSN 1800-427X. April, 2013. Vol. 05, No. 01: 32-35, 2pls.

(C) Taprobanica Private Limited, 146, Kendalanda, Homagama, Sri Lanka.

www.taprobanica.org

\title{
DISCOVERY AND DESCRIPTION OF MALE SPECIMEN OF Coluber bholanathi SHARMA, 1976 (REPTILIA: COLUBRIDAE) FROM HYDERABAD, INDIA
}

Sectional Editor: Gernot Vogel

Submitted: 08 April 2013, Accepted: 15 April 2013

Midathala Seetharamaraju $^{1}$ and Chelmala Srinivasulu ${ }^{1,2}$

${ }^{1}$ Wildlife Biology Section, Department of Zoology, University College of Science, Osmania University, Hyderabad, Andhra Pradesh 500007, India.

${ }^{2}$ E-mail: hyd2masawa@gmail.com

\begin{abstract}
Here we present the first report of the occurrence of an endemic and little known colubrid, Sharma's racer Coluber bholanathi Sharma, 1976, from the urban conglomerate of Hyderabad, Andhra Pradesh, India, with a description of the male specimen including details on the hemipeneal structure.
\end{abstract}

Keywords: Indian snakes, range extension, Sharma's racer, hemipeneal structure

\section{Introduction}

The genus Coluber is represented by three species in India: C. gracilis (Günther, 1862), $C$. vittacaudatus (Blyth, 1854) and C. bholanathi Sharma, 1976. All three are endemic to India with $C$. gracilis known from 19 sites in the states of Rajasthan, Gujarat, Maharashtra and Madhya Pradesh (Günther, 1862; Ingle, 2002; Sharma \& Nagar, 2007; Sharma et al., 2012; Smith, 1943; Vyas et al., 2011; Walmiki et al., 2012), C. vittacaudatus known only from the type locality in northern West Bengal (Blyth, 1854; Das et al., 1998) and C. bholanathi known only from the type locality and one additional site in Andhra Pradesh (Guptha et al., 2012; Sharma, 1976). Here we present the finding of a male C. bholanathi from
Hyderabad, Andhra Pradesh, India, including a detailed description of the specimen.

\section{Materials and Methods}

As part of a biodiversity assessment of the Greater Hyderabad area (centered 17.418 N, 78.403 E), capital of Andhra Pradesh, India, we have been documenting species diversity through regular surveys since the early 1990s. The information on snake diversity occurring within the city limits is primarily based on field surveys, rescue operations, and dead specimens collected by volunteers and students. During our herpetological surveys, a live specimen of C. bholanathi (which was not preserved) was discovered by MS on February 5, 2012, within 
the Golconda Fort complex (17.383 N, 78.401 E). A second freshly killed specimen was collected from locals in the Rethi Gali area (17.386 N, 78.403 E) on March 1, 2013, preserved in $70 \%$ alcohol, and deposited as voucher specimen in the Natural History Museum of Osmania University, Hyderabad, under the catalogue number NHM.OU.REP.12013. The localities where the species have been sighted are highly disturbed, principally urban settlements within the outer ramparts of the Golconda fort that is witnessing unprecedented infrastructure development. The first specimen was found in the main fort area along the wall moving slowly among the crevices of rocks in search of food. The general habitat within the outer ramparts of the Golconda Fort can be described as a mosaic consisting of human settlements with scattered scrub vegetation, agriculture, grassland and rocky outcrops.

We followed standard methods for taking morphometric measurements and pholidosis. The numbers of ventral scales were counted according to Dowling (1951). The number of dorsal scale rows were taken at one head length behind the head, at midbody, and at one head length anterior to the vent. Measurements were taken following Ramadhan et al. (2010). Except total body and tail length, all characters were measured using digital calipers in $\mathrm{mm}$. The hemipenes were manually everted and almost maximally expanded following Zaher and Pudente (2003), and the terminology used are following Dowling \& Savage (1960), and Zaher (1999). One of us (CS) studied the type series housed in the National Zoological Collection of the Zoological Survey of India (ZSI), Kolkata, in April 2005. The distribution map was prepared using ArcGIS 10.0 (ESRI, 2011).

\section{Results}

The adult male snake (now NHM.OU.REP.12013) was killed by locals at 15:30 when it was sighted near a busy settlement area in the Rethi Gali locality. The present record extends the species' range by $130 \mathrm{~km}$ further northwest from its type locality (Fig. 1).

Editor's note: While this article is in press, another manuscript on the same species is accepted by Herpetotropicos journal; see Ganesh et al. 2013.

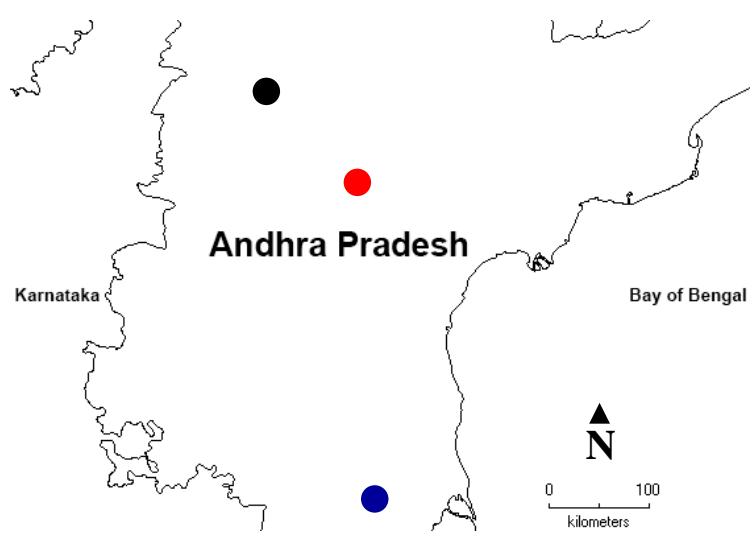

Figure 1: Distribution map of Coluber bholanathi (red, type locality; blue, juvenile record; black, new localities).

\section{Coluber bholanathi Sharma, 1976}

(Figs. 2-4 in plates)

Adult male (522.0 mm SVL), partly damaged in the midbody region; long slender-bodied; snout-vent length $522 \mathrm{~mm}$, tail-length 188 $\mathrm{mm}$; head distinct, broader than the neck region, head length $18.37 \mathrm{~mm}$, head width 9.5 $\mathrm{mm}$, head depth $5.88 \mathrm{~mm}$; rostral width 3.27 $\mathrm{mm}$, rostral height 1.25 , rostral width to height ratio $2: 1$; rostral does not separate the internasals; internasals are slightly smaller than the prefrontals; pupil large and round, eyediameter $2.68 \mathrm{~mm}$, eye to nostril distance 3.37 $\mathrm{mm}$, interorbital distance at anterior borders of the eyes $5.63 \mathrm{~mm}$ and interorbital distance at posterior borders of the eyes $7.5 \mathrm{~mm}$; dorsal scales in 19-19-12 rows; 9 supralabials, 5th and 6th touching the eye, 6th highest and in contact with the anterior lower temporal; 11 infralabials, first 5 touching anterior chinshield, 6th largest; two preoculars, one touching the supralabials smaller than the one touching the supraocular; two postoculars; one loreal; 2 temporal scales in the first row, 2 in the second; ventral scales 203, prominently angulated laterally; mental groove present; anal shield divided; 105 caudals divided except the first three that are undivided; hemipenes strong and unforked with distinct sulcus spermaticus, extending up to the third subcaudal; the everted hemipenes average $6.30 \mathrm{~mm}$ in length. The details of the right hemipenis are as follows: maximum width at base $1.36 \mathrm{~mm}$, narrowest width of the lobe $1.54 \mathrm{~mm}$, maximum width of the lobe $2.31 \mathrm{~mm}$, ratio of the narrowest and maximum width of the lobe 0.66 , length of hemipenis from the base to the most proximal spines on the lobe $1.38 \mathrm{~mm}$, length of spinose 
region $3.53 \mathrm{~mm}$, length of the distal naked region $1.38 \mathrm{~mm} ; 15$ rows of spines, length of the largest spine $0.53 \mathrm{~mm}$.

The ground color of the body and tail is predominantly brown with narrow white blackedged bands on the back that widen on the sides to connect with each other. These bands become progressively faded on the hind body. The tail is distinctively unmarked. A faint black line in the middle of the white bands is characteristic. The top of the head is uniquely patterned with three narrow white black-edged bars, the anterior two bands flanking the eyes are connected by a median transverse band in the middle of the interorbital region. A prominent white spot is present on the supraocular shield on either side. An oblique black stripe from the base of the orbit to the mouth across sixth and seventh supralabials is present. All the labials, chin shields, and lateral scales of the head bear black spots. Iris is dark golden coloured. The lower parts of the body are pinkish-buff, while outer margins of the ventral scales are spotted with black.

\section{Discussion}

Until now Sharma's racer Coluber bholanathi Sharma, 1976 was known only from the type series [the holotype male (ZSI 21337) and two female paratypes (ZSI 21335 and ZSI 21336) collected from Nagarjuna hills $\left(16^{\circ} 31^{\prime} \mathrm{N}, 79^{\circ}\right.$ 14 E), Andhra Pradesh] and a single juvenile specimen (BLT014) deposited at Andhra Pradesh Forest Department's Biodiversity Lab at Tirupati collected from Kapilatheertham, Seshachalam hills $\left(13^{\circ} 39^{\prime} \mathrm{N}, 79^{\circ} 25^{\prime} \mathrm{E}\right)$ (Guptha et al., 2012). The original description by R. C. Sharma is too limited, and owing to its similarity with $C$. gracilis (Günther, 1862), a proper description of the species is provided here. Based on Sharma (1976), Guptha et al. (2012) and the present observations, it is concluded that the Sharma's racer is a nonvenomous colubrid that prefers dry deciduous forest and scrub jungles interspersed with rocky boulders. It is a diurnal snake, as the type series were collected while the specimens were basking in the sun and the specimens in Hyderabad were sighted at 12:00. The specimen at Golconda Fort was observed to be making foraging bouts among the crevices of granite rocks in the fort wall. Although the prey spectrum of this species was not observed, this snake is reported to feed on geckos based on gut analysis (Sharma, 1976).

According to Sharma (1976), Coluber bholanathi is similar to $C$. gracilis and differs from the later in possessing the following characters: rostral shield two times broader than high (vs. as broad as high), dorsal scales in 19:19:15 rows (vs. 21:21:15 rows), ventrals 202-212 (vs. 206-222), and subcaudals 109121 (vs. 118-127). Only the first two characters are robust enough to distinctly separate the two species. In Sharma (1976)'s description of the type series (1 male, 2 females), dorsal count of 19:19:15 were presented, while Guptha et al. (2012) found variation with a male holotype 19:19:12 and 2 female paratypes 19:19:15 and 19:19:13, and the Hyderabad specimen was 19:19:15. This variation could be due to the inconsistency with respect to taking scale counts. In our specimen, the hindbody dorsal scale count taken exactly at the one headlength distance from the vent gave 15 rows of dorsals and gradually decreased to 12 rows of dorsals as the distance reduced from the standard one head-length distance to the vent.

Sharma (1976) mentioned that the hemipenes of the holotype extend up to the sixth subcaudal shield and are devoid of spines. However, our specimen deviates from this in possessing hemipenes bearing spines on the mid-region and extending up to the third subcaudal shield. Although the hemipenes of the holotype has not been studied by us, it is not everted. Thus we refrain from commenting on the veracity of the remark by Sharma (1976) on this aspect and think that, if this character difference proves to be veritable, our specimens might belong to an undescribed species. Due to the lack of information on the ultrastructure of the hemipenes of $C$. gracilis we think that future research in this direction is important for determining the boundaries of the species' geographical range. Furthermore, molecular phylogenetic studies of Coluber species in India should bring clarity to the relationships and divergence patterns among these species, especially with respect to the relationship between Coluber gracilis (Günther, 1862) and Coluber bholanathi Sharma, 1976.

\section{Acknowledgments}

We thank Shri S. Satyanarayana and G. Maruthi Ram (Osmania University, Hyderabad) 
for providing the necessary facilities. We are thankful to Shri A. V. Joseph (Chief Conservator of Forest, Andhra Pradesh), R. Hampaiah (Chairman) and S. N. Jadhav in Andhra Pradesh Biodiversity Board for their constant support and encouragement. We also thank Varad Giri (BNHS), V. Deepak (CES, IISc) and B. H. C. K. Murthy (ZSI) for discussion and sharing information. We acknowledge the Department of Biotechnology, Govt. of India; University Grants Commission, New Delhi and DST-SAP III, Department of Zoology and DBT-ISLARE in Osmania University for supporting our research through different grants.

\section{Literature Cited}

Blyth, E., 1854. Notices and descriptions of various reptiles, new or little known [part 2]. Journal of the Asiatic Society of Bengal. 23: 287302.

Das, I., B. Dattagupta and N. C. Gayen, 1998. History and catalogue of reptile types held in the collection of the Zoological Survey of India. Journal of South Asian Natural History, 3 (2): 121-172.

Dowling, H. G. and J. M. Savage, 1960. A guide to the snake hemipenis: a survey of basic structure and systematic characteristics. Zoologica, 45: 17-30.

Dowling, H. G., 1951. A proposed standard system of counting ventrals in snakes. British Journal of Herpetology, 1: 97-99.

ESRI, 2011. ArcGIS Desktop, Release 10. Environmental Systems Research Institute, Redlands, CA.

Ganesh S. R, D. Adimallaiah and P. K. Kailash, 2013. New locality record of Nagarjun Sagar racer snake Coluber bholanathi Sharma, 1976. Herpetotropicos, 9 (1): accepted.

Günther, A., 1862. On new species of snakes in collection of the British Museum. Annals and Magazine of natural History, London, Ser. 3, 9: 124-132.

Guptha, B., N. V. S. Prasad and D. Veerappan, 2012. Rediscovery and range extension of Coluber bholanathi Sharma, 1976 from Seshachalam hills, Andhra Pradesh, India. Herpetology Notes, 5: 447-448.
Ingle, M., 2002. Ecology and status of ophiofauna of eight districts of Malwa region of Madhya Pradesh. Cobra, 5 (1): 1-5.

Ramadhan, G., D. T. Iskandar and D. R. Subasri, 2010. A new species of cat snake (Serpentes: Colubridae) morphologically similar to Boiga cynodon from the Nusa Tenggara Islands, Indonesia. Asiatic Herpetological Research, 1 (1): 22-30.

Sharma, R. C., 1976. Some observations on ecology and systematics of Coluber bholanathi, a new species of snake from India. Comparative Physiology \& Ecology, 1: 105-107.

Sharma, S. K. and S. Nagar, 2007. First record of Slender racer Coluber gracilis (Günther, 1862) (Serpentes, Colubridae) from Rajasthan. Journal of Bombay Natural History Society, 104 (3): 355.

Sharma, S. K., K. Vijay Kumar and C. Bhatnagar, 2012. Further notes on occurrence of Slender racer Coluber gracilis (Günther, 1862) in Rajasthan, India. Cobra, 6 (2): 16-19.

Smith, M. A., 1943. The fauna of British India, including Ceylon \& Burma. Reptilia \& Amphibia. Vol. III. Taylor \& Francis, London: 583.

Vyas, R., V. V. Patel and M. N. Thakur, 2011. Records of the slender racer Coluber gracilis (Günther, 1862), from Gujarat state with notes on its distribution. Sauria, 33 (2): 51-56.

Walmiki, N., A. Kumbhar and M. Bubesh Guptha, 2012. Range extension of Slender racer (Coluber gracilis Günther, 1862) in India. World Journal of Zoology, 7 (4): 303-305.

Zaher, H. and A. L. C. Pudente, 2003. Hemipenes of Siphlophis (Serpentes, Xenodontinae) and techniques of hemipenial preparation in snakes: A response to Dowling. Herpetological Review, 34: 302-307.

Zaher, H. 1999. Hemipenial morphology of the South American xenodontine snakes, with a proposal for a monophyletic Xenodontinae and a reappraisal of colubroid hemipenes. Bulletin of the American Museum of Natural History, 240. 


\section{PLATE 3}

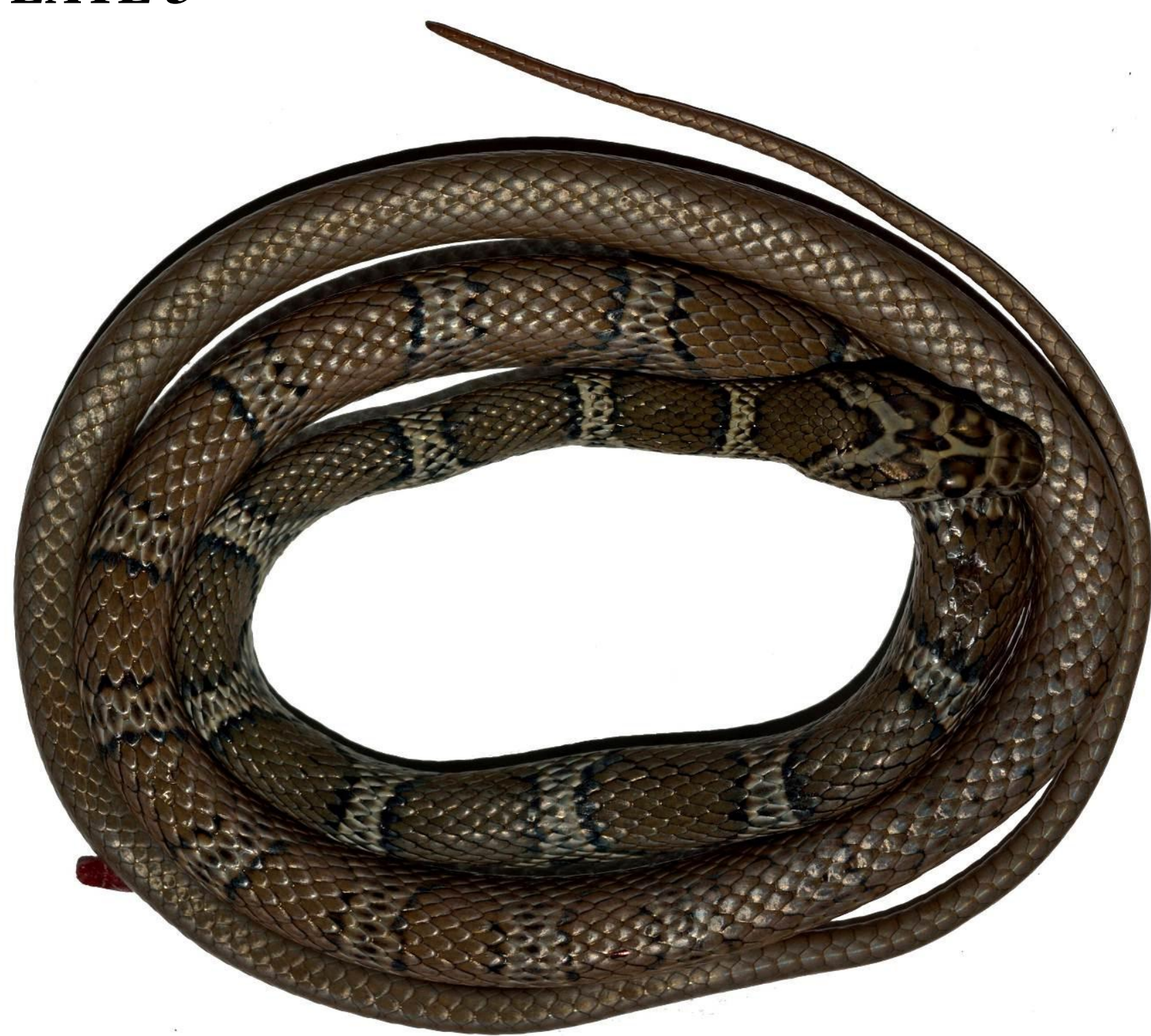

Figure 2: Dorsal view of the adult male Coluber bholanathi (NHM.OU.REP.1-2013)
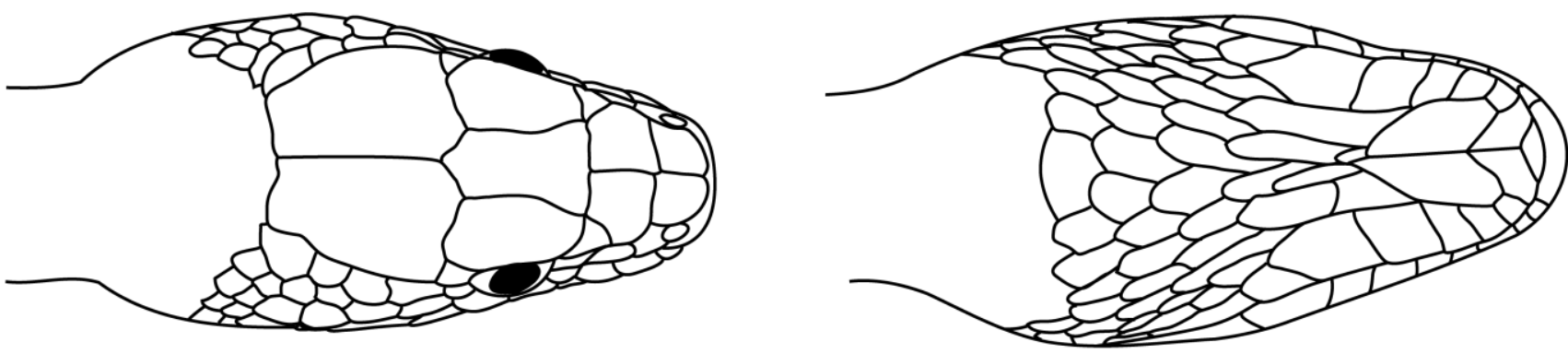

A

B

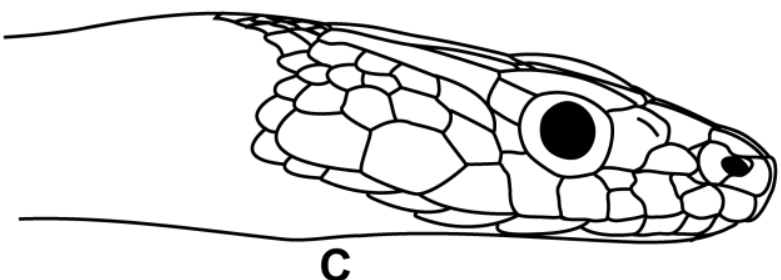

Figure 3: Scalation pattern of the head of adult male Coluber bholanathi (NHM.OU.REP.1-2013) A, dorsal view; B, ventral view; $\mathbf{C}$, lateral view. 


\section{PLATE 4}
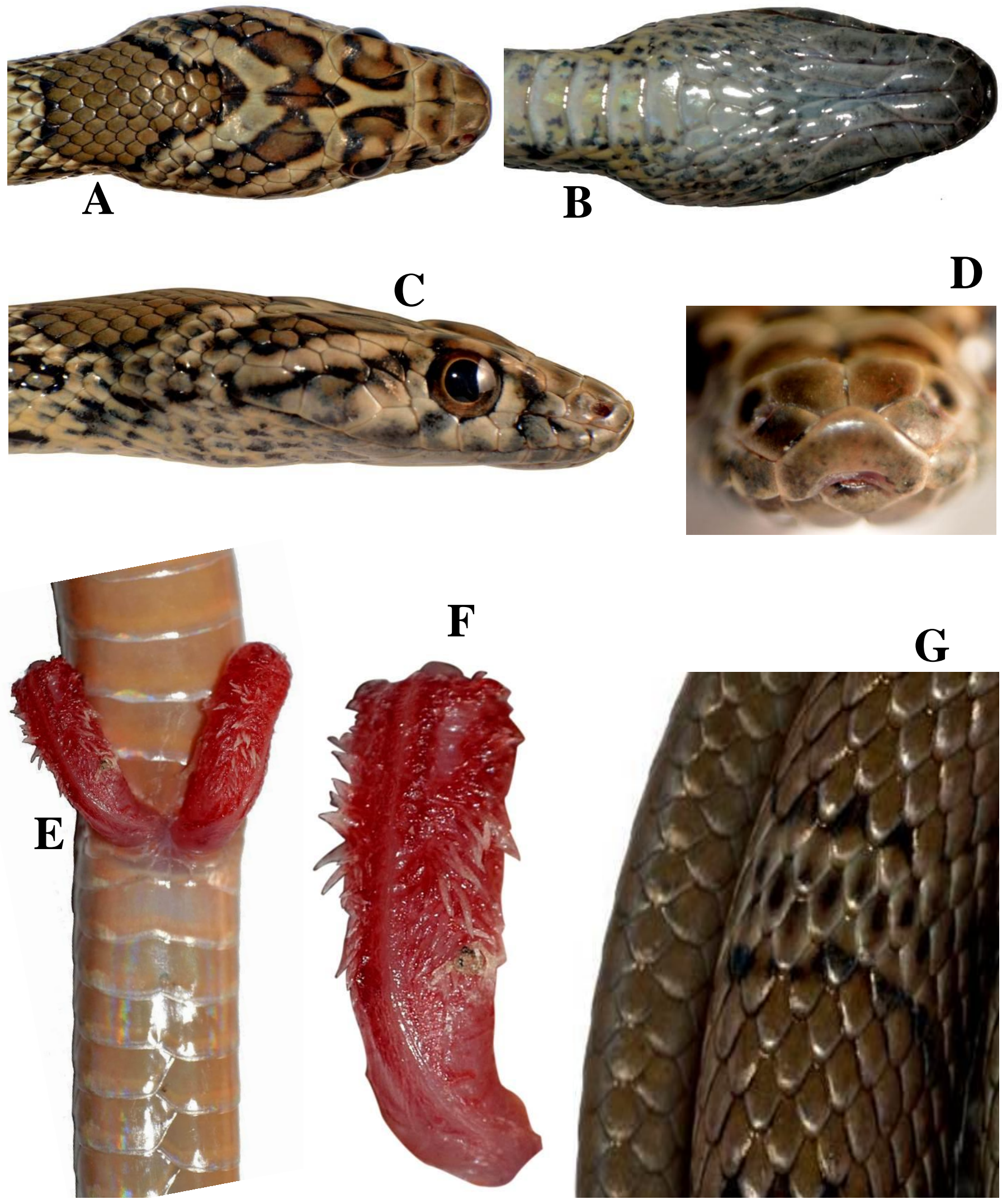

Figure 4: Adult male Coluber bholanathi (NHM.OU.REP.1-2013) A, dorsal view of the head; B, ventral view of the head; $\mathbf{C}$, lateral view of the head; D, frontal view of the rostral shield; $\mathbf{E}$, view of anal and caudal region; $\mathbf{F}$, hemipenis (right, sulcate view) showing pattern of spination and sulcus spermaticus; $\mathbf{G}$, dorsal scales on tail (left) and mid body (right). 